\title{
Schultz and Modified Schultz Polynomials of Coronene Polycyclic Aromatic Hydrocarbons
}

\author{
Mohammad Reza Farahani \\ Department of Applied Mathematics, Iran University of Science and Technology (IUST), \\ Narmak, Tehran 16844, Iran \\ E-mail address: Mr_Farahani@Mathdep.iust.ac.ir, mrfarahani88@gmail.com
}

\begin{abstract}
Let $G=(V ; E)$ be a simple connected graph. The sets of vertices and edges of $G$ are denoted by $V=V(G)$ and $E=E(G)$, respectively. In such a simple molecular graph, vertices represent atoms and edges represent bonds. The distance between the vertices $u$ and $v$ in $V(G)$ of graph $G$ is the number of edges in a shortest path connecting them, we denote by $d(u, v)$. In graph theory, we have many invariant polynomials for a graph $G$. In this research, we computing the Schultz polynomial, Modified Schultz polynomial, Hosoya polynomial and their topological indices of a Hydrocarbon molecule, that we call "Coronene Polycyclic Aromatic Hydrocarbons".
\end{abstract}

Keywords: Topological Indices; Schultz Polynomial; Hosoya Polynomial; Wiener Index; Coronene; Polycyclic Aromatic Hydrocarbons (PAHs)

\section{INTRODUCTION}

Let $G$ be a connected graph. The vertex-set and edge-set of $G$ denoted by $V(G)$ and $E(G)$ respectively, such that in the connected molecular graph $G$, vertices represent atoms and edges represent bonds. In graph theory, the degree of a vertex $v \in V(G)$ is the number of vertices joining to $v$ and denoted by $d_{v}(G)$ (or simpely $d_{v}$ ). If $e$ is an edge of $G$, connecting the vertices $u$ and $v$, then we write $e=u v$. Also $d(u, v)=d(u, v \mid \mathrm{G})$ is the distance between vertices $u$ and $v$ is equal to the length of the shortest path that connects them in $G$.

In chemical graph theory, we have invariant polynomials and topological indices for any molecular graphs. Such that topological indices of molecular graphs and nanostructures are numerical descriptors that are derived from graph of chemical compounds. Such indices based on the distances in graph are widely used for establishing relationships between the structure of molecular graphs and their physicochemical properties.

Usage of topological indices in Biology and Chemistry began in 1947 when chemist Harold Wiener [1] introduced Wiener index to demonstrate correlations between physicochemical properties of organic compounds of molecular graphs. Wiener originally defined his index $(W)$ on trees and studied its use for correlations of physico-chemical properties of alkanes, alcohols, amines and their analogous compounds [2]. 
The Wiener index of a graph $G$ is denoted by $W(G)$ and defined as the sum of distances between all pairs of vertices in simple graph $G$ :

$$
W(G)=\frac{1}{2} \sum_{\mathrm{v} \in \mathrm{V}(\mathrm{G})} \sum_{u \in \mathrm{V}(\mathrm{G})} d(v, u)
$$

where, $d(u, v)$ is the distance between vertices $u$ and $v$.

On based the Wiener index, H. Hosoya introduced the Wiener polynomial (or new Hosoya polynomial) in 1988 [3].

The Hosoya polynomial $H(G, x)$ is defined as:

$$
H(G, x)=\frac{1}{2} \sum_{\mathrm{v} \in \mathrm{V}(\mathrm{G})} \sum_{u \in \mathrm{V}(\mathrm{G})} x^{d(v, u)}
$$

Another based structure descriptors is Schultz index, the Schultz index $(S c)$ was introduced by Harry P. Schultz in 1989 [4-6], as the "molecular topological index" and it is defined by:

$$
S c(\mathrm{G})=\frac{1}{2} \sum_{\{\mathrm{u}, \mathrm{v}\} \in \mathrm{V}(\mathrm{G})}\left(d_{u}+d_{v}\right) d(u, v)
$$

where $d_{u}$ and $d_{v}$ are degrees of vertices $u$ and $v$.

On based the Schultz index S. Klavžar and I. Gutman introduced the Modified Schultz index in 1997 [7-9] and defined as:

$$
S c^{*}(\mathrm{G})=\frac{1}{2} \sum_{\{\mathrm{u}, \mathrm{v}\} \in \mathrm{V}(\mathrm{G})} d(u, v)\left(d_{u} d_{v}\right)
$$

In chemical graph theory, there are two important polynomials for these structure descriptors and "Schultz polynomial" and "Modified Schultz polynomial" of G are defined respectively as:

$$
\begin{aligned}
& S c(\mathrm{G}, \mathrm{x})=\frac{1}{2} \sum_{\{\mathrm{u}, \mathrm{v}\} \in \mathrm{V}(\mathrm{G})}\left(d_{u}+d_{v}\right) x^{d(u, v)} \\
& S^{*}(\mathrm{G}, \mathrm{x})=\frac{1}{2} \sum_{\{\mathrm{u}, \mathrm{v}\} \in \mathrm{V}(\mathrm{G})}\left(d_{u} d_{v}\right) x^{d(u, v)}
\end{aligned}
$$

These based structure descriptors and their polynomials studied and computed in many papers [7-35] and also the Hosoya polynomial and Wiener index of some molecular graph computed [7,12,13,23,36-43]. In this research, we computing the Schultz polynomial, Modified Schultz polynomial, Hosoya polynomial and their topological indices of a Hydrocarbon molecule, that we call "Coronene Polycyclic Aromatic Hydrocarbons". 


\section{RESULTS AND DISCUSSION}

In chemical, physics and nano sciences, we have the appealing structure, especially symmetric structure with chemical constitution purporting. One of the molecular graphs is Benzenoid System. Since molecule benzene $\left(\mathrm{C}_{6} \mathrm{H}_{6}\right)$ is more practical in the chemical, physics and nano science, we lionize its structure.

In this section we compute structure descriptors and their polynomials of a family of Coronene Polycyclic Aromatic Hydrocarbons (Figure 1). Coronene $\mathrm{PAH}_{2}$ is second members of Polycyclic Aromatic Hydrocarbon molecules. Polycyclic aromatic hydrocarbons $P A H_{n}$ family have very similar properties to one of famous family of Benzenoid System that called Circumcoronene Homologous Series of Benzenoid $H_{k}$. Polycyclic Aromatic Hydrocarbons and Circumcoronene Series of Benzenoid are two families of hydrocarbon molecules, such that their structure is consisting of Benzene $C_{6} H_{6}$ or cycles with length six $C_{6}$ by defferent componds. In a series of papers, some properties and more historical details of hydrocarbon molecules are studed [44-57] and some applications of Benzenoid system are presented in many papers [58-74].

By focus on the structure of Coronene Polycyclic Aromatic Hydrocarbons $\mathrm{PAH}_{2}$ (or $\mathrm{C}_{24} \mathrm{H}_{12}$ ) and definitions of Schultz polynomial, Modified Schultz polynomial, Hosoya polynomial and their topological indices, we have following theorems.

Theorem 1. Let $\mathrm{PAH}_{2}$ be the secobd members of Polycyclic Aromatic Hydrocarbons (PAHs). Then

- The Schultz polynomial of $\mathrm{PAH}_{2}$ is equal to:

$$
\mathrm{Sc}\left(\mathrm{PAH}_{2}, x\right)=228 x^{1}+384 x^{2}+498 x^{3}+528 x^{4}+486 x^{5}+384 x^{6}+276 x^{7}+132 x^{8}+24 x^{9}
$$

- The Modified Schultz polynomial of $\mathrm{PAH}_{2}$ is equal to:

$$
S c *\left(P A H_{2}, x\right)=306 x^{1}+504 x^{2}+627 x^{3}+636 x^{4}+561 x^{5}+420 x^{6}+258 x^{7}+90 x^{8}+12 x^{9}
$$

- Hosoya polynomial of $P A H_{1}$ is equal to

$$
H\left(P A H_{2}, x\right)=42 x^{1}+72 x^{2}+99 x^{3}+108 x^{4}+105 x^{5}+84 x^{6}+66 x^{7}+42 x^{8}+12 x^{9}
$$

Theorem 2. Consider Coronene Polycyclic Aromatic Hydrocarbons $P A H_{2}$. Then respectively, the Schultz, Modified Schultz and Wiener indices of $\mathrm{PAH}_{2}$ are equal to:

$$
\begin{gathered}
S c\left(\mathrm{PAH}_{2}\right)=12540 \\
\mathrm{Sc}^{*}\left(\mathrm{PAH}_{2}\right)=13698 \\
W\left(\mathrm{PAH}_{2}\right)=2850
\end{gathered}
$$

Proof of Theorem 1: Consider Coronene Polycyclic Aromatic Hydrocarbons $\mathrm{PAH}_{2}$. By according to Figure1, one can see that $\mathrm{PAH}_{2}$ have 24 carbon $(\mathrm{C})$ atoms and 12 hydrogen $(\mathrm{H})$ atoms. Since $C_{24} H_{12}$ have 36 verices/atoms, thus there are $630=\left(\begin{array}{c}36 \\ 2\end{array}\right)$ distinct shortest path between all vertices of $\mathrm{PAH}_{2}$. 


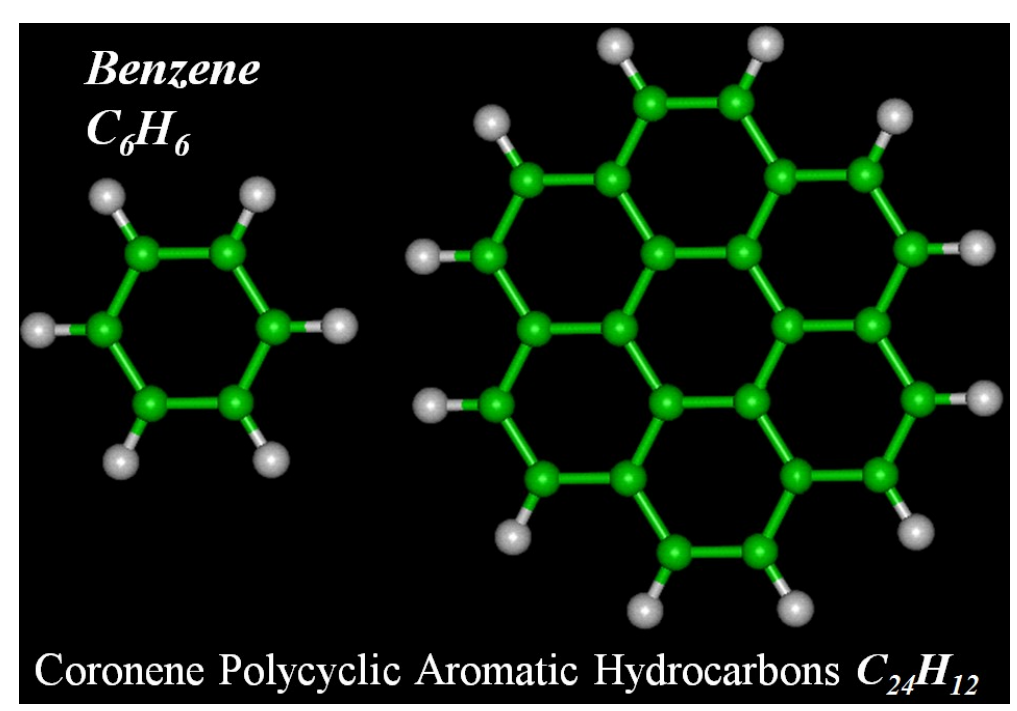

Figure 1. Benzene molecules $\mathrm{C}_{6} \mathrm{H}_{6}$ and Coronene Polycyclic Aromatic Hydrocarbons $\mathrm{PAH}_{2}$.

Now, for a graph $G$, let $D_{s}(G)=\{\{u, v\} \in V(G) \mid d(u, v)=s\}$ is set of all pairs of vertices with distance $s$, such that $\left|D_{s}(G)\right|=d(G, s)$. Suppose the diameter $d(G)$ is the longest topological distance (maximum $s$ ) in $G$. Thus, the Hosoya polynomial and the Wiener index of $G$ are redefined as:

$$
\begin{gathered}
H(G, x)=\sum_{s=0}^{d(G)} d(G, s) . x^{s} \\
W(G)=\sum_{s=0}^{d(G)} d(G, s) . s
\end{gathered}
$$

and also the Schultz and Modified Schultz polynomials of $G$ can be defined as:

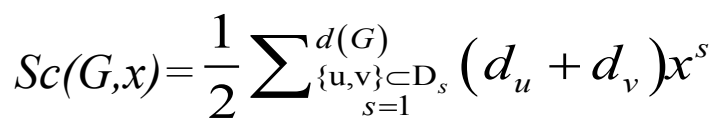

$$
\begin{aligned}
& S c^{*}(G, x)=\frac{1}{2} \sum_{\substack{\{\mathrm{u}, \mathrm{v}\} \subset \mathrm{D}_{s} \\
s=1}}^{d(G)}\left(d_{u} d_{v}\right) x^{s}
\end{aligned}
$$

By according to Figure1, one can see that there are nine subsets of $V(G)$. In other words, $V(G)=\bigcup^{\top} D_{s}(G)$ and obviously $\left|D_{1}\right|+\left|D_{2}\right|+. .+\left|D_{9}\right|=630$.

Now, by definition of $D_{s}(G)$, it is easy to see that for $d(u, v)=1, D_{1}\left(P A H_{2}\right)=E\left(P A H_{2}\right)$, then $\left|D_{1}\right|=42$ and is equal to $\left|E\left(P A H_{2}\right)\right|$. From $E\left(P A H_{2}\right)$, we see that for 12 hydrogen $(\mathrm{H})$ atoms $\left|D_{l}^{H C}\right|=\left|\left\{(u, v) \mid u, v \in V\left(P A H_{2}\right), d(u, v)=1 \& d_{u}+d_{v}=4, d_{u} \times d_{v}=3\right\}\right|=12$. So, we have three sentences $12 x^{1}, 48 x^{1}$ and $36 x^{1}$ of the Hosoya, Schultz and Modified Schultz polynomials, respectively. And for carbon (C) atoms: 


$$
\left|D_{1}^{C C}\right|=\left|\left\{(u, v) \mid u, v \in V\left(P A H_{2}\right), d(u, v)=1 \& d_{u}+d_{v}=6, d_{u} \times d_{v}=9\right\}\right|=30
$$

Thus, we have three terms $30 x^{1}, 180 x^{1}, 270 x^{1}$ of the above polynomials, respectively.

Therefore, we have three frist sentences $42 x^{1}, 228 x^{1}$ and $306 x^{1}$ of the Hosoya, Schultz and Modified Schultz polynomials, respectively.

Now, suppose $d(u, v)=2, D_{2}\left(P_{A H_{2}}\right)$ have two partitions as follows:

1. For carbon atoms:

$$
\left|D_{2}{ }^{C C}\right|=\left|\left\{(u, v) \mid u, v \in V\left(P A H_{2}\right), d(u, v)=2 \& d_{u}+d_{v}=6, d_{u} \times d_{v}=9\right\}\right|=48 .
$$

2. For hydrogen atoms:

$$
\left|D_{2}{ }^{H C}\right|=\left|\left\{(u, v) \mid u, v \in V\left(P A H_{2}\right), d(u, v)=2 \& d_{u}+d_{v}=4, d_{u} \times d_{v}=3\right\}\right|=2 \times 12 \text {. }
$$

Hence, we have three terms $48 x^{2}+24 x^{2}, 288 x^{2}+96 x^{2}, 432 x^{2}+72 x^{2}$ of the Hosoya, Schultz and Modified Schultz polynomials, respectively.

Now, If $d(u, v)=3$, then $\left|D_{3}\left(P_{A H_{2}}\right)\right|=99$ and there are three subsets of it.

1. For hydrogen $(\mathrm{H})$ atoms:

$$
\left|D_{3}{ }^{H H}\right|=\left|\left\{(u, v) \mid u, v \in V\left(P A H_{2}\right), d(u, v)=3 \& d_{u}+d_{v}=2, d_{u} \times d_{v}=1\right\}\right|=6 .
$$

2. For paths between carbon and hydrogen atoms as distance 3 :

$$
\left|D_{3}{ }^{C H}\right|=\left|\left\{(u, v) \mid u, v \in V\left(P A H_{2}\right), d(u, v)=3 \& d_{u}+d_{v}=4, d_{u} \times d_{v}=3\right\}\right|=3 \times 12 .
$$

3. For carbon atoms:

$$
\left|D_{3}{ }^{C C}\right|=\left|\left\{(u, v) \mid u, v \in V\left(P A H_{2}\right), d(u, v)=3 \& d_{u}+d_{v}=6, d_{u} \times d_{v}=9\right\}\right|=57 .
$$

So, we have three sentences $6 x^{3}+36 x^{3}+57 x^{3}, 12 x^{3}+144 x^{3}+342 x^{3}$ and $6 x^{3}+108 x^{3}+513 x^{3}$ of the Hosoya, Schultz and Modified Schultz polynomials of $\mathrm{PAH}_{2}$, respectively.

If $d(u, v)=4$, then $\left|D_{4}\left(P A H_{2}\right)\right|=108$ and we have three subsets of $D_{4}$ of $P A H_{2}$ as

1. For hydrogen $(\mathrm{H})$ atoms:

$$
\left|D_{4}^{H H}\right|=\left|\left\{(u, v) \mid u, v \in V\left(P A H_{2}\right), d_{u}+d_{v}=2, d_{u} \times d_{v}=1\right\}\right|=6 .
$$

2. For paths between carbon and hydrogen atoms:

$$
\begin{gathered}
\left|D_{4}{ }^{C H}\right|=\mid\left\{(u, v) \mid u, v \in V\left(P A H_{2}\right), d_{u}+d_{v}=4,\right. \\
\left.d_{u} \times d_{v}=3\right\} \mid=4 \times 12 .
\end{gathered}
$$

3. For carbon atoms:

$$
\left|D_{4}{ }^{C C}\right|=\left|\left\{(u, v) \mid u, v \in V\left(P A H_{2}\right), d(u, v)=4 \& d_{u}+d_{v}=6, d_{u} \times d_{v}=9\right\}\right|=54 .
$$

Generally, we will have three sentences $6 x^{4}+48 x^{4}+54 x^{4}, 12 x^{4}+192 x^{4}+324 x^{4}$ and $6 x^{4}+144 x^{4}+486 x^{4}$ of the Hosoya, Schultz and Modified Schultz polynomials.

For $d(u, v)=5,\left|D_{5}\left(P_{A} H_{2}\right)\right|=\left|\left\{(u, v) \mid u, v \in V\left(P A H_{2}\right), d(u, v)=5\right\}\right|=105$, therefore

1. For hydrogen atoms:

$$
\left|D_{5}{ }^{H H}\right|=\left|\left\{(u, v) \mid u, v \in V\left(P A H_{2}\right), d(u, v)=5 \& d_{u}+d_{v}=2, d_{u} \times d_{v}=1\right\}\right|=12 .
$$

2. For paths between $\mathrm{C}$ and $\mathrm{H}$ atoms: 


$$
\left|D_{5}{ }^{C H}\right|=\left|\left\{(u, v) \mid u, v \in V\left(P A H_{2}\right), d(u, v)=5 \& d_{u}+d_{v}=4, d_{u} \times d_{v}=3\right\}\right|=48 .
$$

3. For carbon atoms:

$$
\left|D_{5}{ }^{C C}\right|=\left|\left\{(u, v) \mid u, v \in V\left(P A H_{2}\right), d(u, v)=5 \& d_{u}+d_{v}=6, d_{u} \times d_{v}=9\right\}\right|=45 .
$$

So, $12 x^{5}+48 x^{5}+45 x^{5}, 24 x^{5}+192 x^{5}+270 x^{5}$ and $12 x^{5}+144 x^{5}+405 x^{5}$ are three terms of the Hosoya, Schultz and Modified Schultz polynomials of $\mathrm{PAH}_{2}$, respectively.

If $d(u, v)=6$ or 7 , then $\left|D_{6}\left(P A H_{2}\right)\right|=84$ and $\left|D_{7}\left(P A H_{2}\right)\right|=66$, thus we have three subsets of $D_{6}$ and $D_{7}$ simillary as follow:

1. For hydrogen $(\mathrm{H})$ atoms:

$\left|D_{6}{ }^{H H}\right|=\left|D_{7}^{H H}\right|=\left|\left\{(u, v) \mid u, v \in V\left(P A H_{2}\right), d(u, v)=6 \& d_{u}+d_{v}=2, d_{u} \times d_{v}=1\right\}\right|=6$.

2. For paths between carbon and hydrogen atoms:

$$
\left|D_{6}{ }^{C H}\right|=\left|D_{7}{ }^{H H}\right|=\left|\left\{(u, v) \mid u, v \in V\left(P A H_{2}\right), d_{u}+d_{v}=4, d_{u} \times d_{v}=3\right\}\right|=4 \times 12 .
$$

3. For carbon atoms: |

$$
\begin{gathered}
D_{6}{ }^{C C}|=|\left\{(u, v) \mid u, v \in V\left(P A H_{2}\right), d(u, v)=6 \& d_{u}+d_{v}=6, d_{u} \times d_{v}=9\right\} \mid=30 \\
\text { and }\left|D_{7}{ }^{C C}\right|=12 .
\end{gathered}
$$

So, we have three terms $(6+48+30) x^{6}+(6+48+12) x^{7},(12+192+180) x^{6}+(12+192+72) x^{7}$ and $(6+144+270) x^{6}+(6+144+108) x^{7}$ of the Hosoya, Schultz and Modified Schultz polynomials of $\mathrm{PAH}_{2}$, respectively.

Now, If $d(u, v)=8$, then $\left|D_{8}\left(P A H_{2}\right)\right|=42$ and since there is not any path between carbon atoms, thus two subsets of $D_{8}\left(\mathrm{PAH}_{2}\right)$ are as follow:

1. For $\mathrm{H}$ atoms:

$$
\left|D_{8}{ }^{H H}\right|=\left|\left\{\{u, v\} \subset V\left(P A H_{2}\right) \mid d(u, v)=8 \& d_{u}+d_{v}=2, d_{u} \times d_{v}=1\right\}\right|=18 .
$$

2. For paths between $\mathrm{C}$ and $\mathrm{H}$ atoms:

$$
\left|D_{8}{ }^{C H}\right|=\left|\left\{\{u, v\} \subset V\left(P A H_{2}\right) \mid d_{u}+d_{v}=4, d_{u} \times d_{v}=3\right\}\right|=2 \times 12 .
$$

And we have three sentences $18 x^{8}+24 x^{8}, 36 x^{8}+96 x^{8}$ and $18 x^{8}+72 x^{8}$ of the Hosoya, Schultz and Modified Schultz polynomials, respectively.

Finally for $d(u, v)=9,\left|D_{9}\left(P_{A} H_{2}\right)\right|=\mid\left\{(u, v) \mid u, v \in V\left(P A H_{2}\right), d(u, v)=9 \& d_{u}+d_{v}=2, d_{u} \times d_{v}\right.$ $=1\}|=| D_{9}{ }^{H H} \mid=12$. Therefore last sentences in above polynomials is $12 x^{9}, 24 x^{9}$ and $12 x^{9}$, respectively.

Thus totally, the Hosoya polynomial of Coronene Polycyclic Aromatic Hydrocarbons $\mathrm{PAH}_{2}$ is equal to:

$$
H\left(P A H_{2}, x\right)=42 x^{1}+72 x^{2}+99 x^{3}+108 x^{4}+105 x^{5}+84 x^{6}+66 x^{7}+42 x^{8}+12 x^{9}
$$

and the Schultz polynomial of $\mathrm{PAH}_{2}$ is equal to:

$$
\mathrm{Sc}\left(\mathrm{PAH}_{2}, x\right)=228 x^{1}+384 x^{2}+498 x^{3}+528 x^{4}+486 x^{5}+384 x^{6}+276 x^{7}+132 x^{8}+24 x^{9}
$$

In finally, the Modified Schultz polynomial of $\mathrm{PAH}_{2}$ is equal to: 


$$
S c *\left(P A H_{2}, x\right)=306 x^{1}+504 x^{2}+627 x^{3}+636 x^{4}+561 x^{5}+420 x^{6}+258 x^{7}+90 x^{8}+12 x^{9}
$$

Here, we complete the proof of Theorem 1.

Proof of Theorem 2: Let $\mathrm{PAH}_{2}$ be the second member of Polycyclic Aromatic Hydrocarbons. By using the dfinitions of the Schultz, Modified Schultz and Wiener indices of a graph and reference to Proof of Theorem 1, we will have

$$
\begin{aligned}
& S c\left(P A H_{2}\right)=\left.\frac{\partial S c\left(P A H_{2}, \mathrm{x}\right)}{\partial x}\right|_{x=1} \\
& =(228 \times 1)+(384 \times 2)+(498 \times 3)+(528 \times 4)+(486 \times 5)+(384 \times 6)+ \\
& (276 \times 7)+(132 \times 8)+(24 \times 9)=12540
\end{aligned}
$$

And finally the Wiener index of of Coronene Polycyclic Aromatic Hydrocarbons $\mathrm{PAH}_{2}$ is equal to:

$$
\begin{gathered}
W\left(P A H_{2}\right)=\sum_{s=1}^{d\left(P A H_{2}\right)} i . d\left(P A H_{2}, s\right)=(42 \times 1)+(72 \times 2)+(99 \times 3)+(108 \times 4)+(105 \times 5) \\
+(84 \times 6)+(66 \times 7)+(42 \times 8)+(12 \times 9)=2850
\end{gathered}
$$

Here, the proof of Theorem 2 is complete.

\section{CONCLUSION}

In this paper, counting polynomials called "Schultz $S c(\mathrm{G})=\frac{1}{2} \sum_{\{\mathrm{u}, \mathrm{v}\} \subset \mathrm{V}(\mathrm{G})}\left(d_{u}+d_{v}\right) d(u, v)$, Modified Schultz $\quad S c^{*}(\mathrm{G})=\frac{1}{2} \sum_{\{\mathrm{u}, \mathrm{v}\} \in \mathrm{V}(\mathrm{G})} d(u, v)\left(d_{u} d_{v}\right) \quad$ and $\quad$ Hosoya $H(G, x)=\frac{1}{2} \sum_{\mathrm{v} \in \mathrm{V}(\mathrm{G})} \sum_{u \in \mathrm{V}(\mathrm{G})} x^{d(v, u)}$ ” of Coronene Polycyclic Aromatic Hydrocarbons $\mathrm{PAH}_{2}$ were determined. See above theorems. 


\section{References}

[1] H. Wiener, J. Amer. Chem. Soc. 69 (1947) 17-20.

[2] P.V. Khadikar, S. Karmarkar, Acta Chim. Slov. 49 (2002) 755-771.

[3] H. Hosoya. Discrete Appl. Math. 19 (1988) 239-257.

[4] H.P. Schultz. J. Chem. Inf. Comput. Sci. 29 (1989) 227-228.

[5] H.P. Schultz, J. Chem. Inf. Comput. Sci. 40 (2000) 1158-1159.

[6] H.P. Schultz, T.P. Schultz, J. Chem. Inf. Comput. Sci. 40 (2000) 107-112.

[7] S. Klavžar, I. Gutman. Disc. Appl. Math. 80 (1997) 73-81.

[8] S. Klavžar, I. Gutman, J. Chem. Inf. Comput. Sci. 36(5) (1996) 1001-1003.

[9] S. Klavžar, I. Gutman, J. Chem. Inf. Comput. Sci. 37(4) (1997) 741-744.

[10] D.J. Klein, Z. Mihalic, D. Plavsic, N. Trinajstic, J. Chem. Inf. Comput. Sci. 32 (1992) 304-305.

[11] A.A. Dobrynin, A.A. Kochetova,. Chem. Inf. Comput. Sci. 34 (1994) 1082-1086.

[12] I. Gutman, J. Chem. Inf. Comput. Sci. 34 (1994) 1087-1089.

[13] W.C. Shiu, P.C.B. Lam, Discrete Appl. Math. 73 (1997) 101-111.

[14] A.A. Dobrynin, Croat. Chem. Acta 72 (1999) 869-874.

[15] I. Tomescu, Discrete Appl. Math. 98 (1999) 159-163.

[16] A.A. Dobrynin, R. Entringer, I. Gutman, Acta Appl. Math. 66 (2001) 211-249.

[17] A.A. Dobrynin, I. Gutman, S. Klavzar, P. Zigert, Acta Appl. Math. 72 (2002) 247-294.

[18] B. Zhou, MATCH Commun. Math. Comput. Chem. 56 (2006) 189-194.

[19] H. Deng, MATCH Commun. Math. Comput. Chem. 57 (2007) 677-684.

[20] I. Tomescu, Discrete Appl. Math. 156 (2008) 125-130

[21] O. Bucicovschi, S.M. Cioaba, Discrete Appl. Math. 156 (2008) 3518-3521.

[22] S. Chen, Q. Jang, Y. Hou, MATCH Commun. Math. Comput. Chem. 59 (2008) 429-435.

[23] A. Iranmanesh, Y. Alizadeh. American Journal of Applied Sciences 5(12) (2008) 17541757.

[24] M. Eliasi, B. Taeri, Appl. Anal. Discrete Math. 2 (2008) 285-296.

[25] I. Tomescu, Discrete Math. 309 (2009) 2745-2748.

[26] H. Hua, MATCH Commun. Math. Comput. Chem. 61 (2009) 643-651.

[27] Y. Alizadeh, A. Iranmanesh, S. Mirzaie, Digest. J. Nanomater. Bios. 4(1) (2009) 7-10.

[28] O. Halakoo, O. Khormali,A. Mahmiani, Digest. J. Nanomater. Bios. 4(4) (2009) 687691.

[29] A. Iranmanesh, Y. Alizadeh, Digest. J. Nanomater. Bios. 4(1) (2009) 607-611.

[30] A. Iranmanesh, Y. Alizadeh, Digest. J. Nanomater. Bios. 4(1) (2009) 67-72. 
[31] A.Ilic, S.Klavzar, D. Stevanovic. MATCH Commun. Math. Comput. Chem. 63 (2010) 411-424.

[32] A. Heydari, Digest. J. Nanomater. Bios. 5(1) (2010) 51-56.

[33] M.R. Farahani, M.P. Vlad. Studia Universitatis Babes-Bolyai Chemia 4 (2012) 55-63.

[34] M.R.Farahani., Journal of Applications of Discrete Mathematics 1(1) (2013) 1-8.

[35] M.R. Farahani, Journal of Applied Mathematics \& Informatics 31(5-6) (2013).

[36] M.V. Diudea, MATCH Commun. Math. Comput. Chem. 45 (2002) 109-122.

[37] Sh. Xu, H. Zhang, J. Math. Chem. 43(2) (2008) 852-863.

[38] A.R. Ashrafi, M. Ghorbani, Digest. J. Nanomater. Bios. 4(2) (2009) 389-393.

[39] A.R. Ashrafi, H. Shabani, Digest. J. Nanomater. Bios. 4(3) (2009) 453-457.

[40] H. Shabani, A.R. Ashrafi, Digest. J. Nanomater. Bios. 4(3) (2009) 423-428.

[41] K. Xu, Digest. J. Nanomater. Bios. 6(1) (2011) 265-270.

[42] M.R. Farahani, Int. J. Computational Sciences \& Applications 3(6) (2013).

[43] M.R. Farahani. Iranian Journal of Mathematical Chemistry 4(2) (2013) 235-240.

[44] S.E. Stein, R.L. Brown, J. Am. Chem. Soc. 109 (1987) 3721-372.

[45] U.E. Wiersum, L.W. Jenneskens in Gas Phase Reactions in Organic Synthesis, (Ed.: Y. Valle. e), Gordon and Breach Science Publishers, Amsterdam, The Netherlands, (1997), 143-194.

[46] M. Wagner, K.M. llen, Carbon. 36 (1998) 833- 83.

[47] A. M. Craats, J.M. Warman, K.M. llen, Y. Geerts, J. D. Brand, Adv. Mater. 10 (1998) 36-38.

[48] A. J. Berresheim, M.M. ller, K.M. llen, Chem. Rev. 99 (1999) 1747-1785.

[49] C.W. Bauschlicher, Jr, E.L.O. Bakes, Chem. Phys. 262 (2000) 285-291.

[50] F. Dietz, N. Tyutyulkov, G. Madjarova, K.M. llen, J. Phys. Chem. B 104 (2000) 1746-1761.

[51] F. Dtz, J.D. Brand, S. Ito, L. Ghergel, K.M. 1len, J. Am. Chem. Soc. 2000, 122, 7707-7717.

[52] K.Yoshimura, L. Przybilla, S. Ito, J.D. Brand, M. Wehmeir, H.J. Rder, K.M. llen, Macromol, Chem. Phys. 202 (2001) 215-222.

[53] S.E. Huber, A. Mauracher, M. Probst, Chem. Eur. J. 9 (2003) 2974-2981.

[54] K. Jug, T. Bredow, J. Computational Chemistry 25 (2004) 1551-1567.

[55] M.R. Farahani, Advances in Materials and Corrosion 1 (2013) 65-69.

[56] M.R. Farahani, J. Chem. Acta 2 (2013) 70-72.

[57] A. Soncini, E. Steiner, P.W. Fowler, R.W. A. Havenith, L.W. Jenneskens. Perimeter Effects on Ring Currents in Polycyclic Aromatic Hydrocarbons: Circumcoronene and Two Hexabenzocoronenes. Manuscript.

[58] M. Goldberg, Tohoku Math. J. 43 (1937) 104-108.

[59] J. Brunvoll, B.N. Cyvin, S.J. Cyvin. J. Chem. of Comput. Sci. 27 (1987) 171-177. 
[60] S. Klavžar, I. Gutman, B. Mohar. J. Chem. Int. Comput. Sci. 35 (1995) 590-593.

[61] J.R. Dias, MATCH Commun. Math. Comput. Chem. 4 (1996) 57-85.

[62] A. Dress, G. Brinkmann, MATCH Commun. Math. Comput. Chem. 33 (1996) 87-100.

[63] I. Gutman, S. Klavžar. ACH Mo dels Chem. 133 (1996) 389-399.

[64] E. Estrada, L. Torres, L. Rodriguez and I. Gutman. Indian J. Chem. 37, (1998), 849.

[65] V. Chepoi, S. Klavžar. Discrete Mathematics 192 (1998) 27-39.

[66] I. Gutman, S. Klavžar, M. Petkovsek, P. Zigert, MATCH Commun. Math. Comput. Chem. 43 (2001) 49-66.

[67] K. Salem, S. Klavžar, I. Gutman, Discrete Mathematics 13(8) (2003) 306.

[68] M.V. Diudea, J. Chem. Inf. Model 45 (2005) 1002-1009.

[69] M.V. Diudea, M. Ştefu, P.E. John, A. Graovac, Croat. Chem. Acta 79 (2006) 355-362.

[70] S. Klavžar, MATCH Commun. Math. Comput. Chem. 60 (2008) 255-274.

[71] M.R. Farahani, Adv. Mater. Corrosion. 2 (2013) 16-19.

[72] Mohammad Reza Farahani, International Letters of Chemistry, Physics and Astronomy 11(1) (2014) 74-80.

[73] Mohammad Reza Farahani, International Letters of Chemistry, Physics and Astronomy 12 (2014) 56-62.

[74] Mohammad Reza Farahani, International Letters of Chemistry, Physics and Astronomy 12 (2014) 63-68. 